\title{
The Research on Wetland Ecological Engineering Database Based on 3S Technology
}

\author{
Liwei Liu and Yinlong Zhang*
}

College of Biology and the Environment, Nanjing Forestry University, Nanjing, JiangSu, China

\begin{abstract}
Wetlands are important to the survival of the earth environment and ecosystems, along with the extent of the ecological study of regional governance continues to accelerate, the regulators have implemented various ecological management project management process kinds of data and information related to the increasing range. The traditional data management model is difficult to meet the current needs of engineering data management; On the other hand, the study area of wetland ecological management is a very large and complex systems engineering, the development of ecological planning for the study area, researchers need to master the ecological evolution and resource development data for the study area have a comprehensive understanding of the historical evolution. Therefore, the establishment of research and development based on 3S technology which research regional ecological engineering design data management needs of ecological engineering database is very important for the planning of the regional ecological engineering, management, decision-making, assessment, analysis and dynamic monitoring to provide technical support to achieve the dynamic management of ecological engineering, comparative study of regional environmental and ecological data at different times to seek more rational governance.
\end{abstract}

Keywords: Engineering database, 3S technology, the wetland ecology.

\section{INTRODUCTION}

Wetland is important to the survival of the Earth environment and ecosystems, with a stable environment, species protection and resource utilization of functional genes, known as the kidney of nature, biological gene bank and the Cradle of Humankind, in improving the climate, against floods, water purification, maintain species genetic diversity and maintain the ecological balance of the area and so there are other systems irreplaceable role. But in recent years, rapid population growth, accelerating urbanization and the rapid development of industry and agriculture, as well as the irrational exploitation of wetland resources, have led to the degradation of wetlands, wetland functions in a serious threat [1].

Currently, computer technology has been widely used, inputs, and the application of different sizes, different functions of wetland resources information management system, has achieved good economic, social and ecological benefits. With the study of regional ecological protection project on the urgent need for comprehensive application of technology, $3 \mathrm{~S}$ technology, environmental engineering, database technology, information management systems, decision support systems used in wetland areas to mature. Due to the geographical study area a wide range of complex and diverse natural conditions, and traffic inconvenience, if the traditional survey research methods, takes a huge human, material and financial resources, the survey cycle is relatively long. Using $3 \mathrm{~S}$ technology, the basic situation in a relatively short time with less human, financial grasp of wetland resources, evaluate the use of wetland status and trends, and provide scientific basis for optimizing the use and protection of wetlands [2].

\section{RESEARCH STATUS OF PROJECT DATABSE}

\subsection{The Research Status of Foreign Engineering Data- base}

Since the 1970s, E.F. Codd researcher has proposed the relational database model, database researchers have been doing ongoing exploration and research in the database field, a number of foreign countries have developed broadly in line with the requirements of practical engineering systems. Relatively well-known American company launched Primavera P3 (Primavera Project Planner referred to P3), mainly for system planning, project management, encoding settings, detailed planning, schedule calculation and statistical analysis; Carnegie Mellon University developed a simulation, monitoring, scheduling, CALLISTO systems to manage large projects; Microsoft companies have developed software Microsoft Project schedule management, project management, can help users to establish the project schedule, analysis and optimization of the schedule, when the implementation of the plan is changed, the progress targets control and management; CAD Norwegian Institute for developed industrial center/CAM applications, database management systems TORNADO, the system provides the user with a very flexible mesh model definition language, TORNADO Version5.0 also supports the definition of complex objects and treatment, in terms of data types also increased the dynamic arrays [3]. 


\subsection{The Research Status of Domestic Engineering Data- base}

Our database is mainly used in the field of engineering machinery, roads, railways, oil and flood control. Such as the establishment of Wang and other Windows-based platform for the development of object-oriented systems Die CAD engineering database systems to meet the mold design and assembly management, device management and mold design results management, engineering CAD systems solve the low efficiency and convenience in data processing engineering CAD software development and maintenance; Hongrong Jing has established with SQL Server2000 as the backend database to Java for Web Service development tools support the development of subway car body engineering database system, complete reception function queries, visual query and parameterized queries functional design, effective managing body of the product development data to support the development of a parallel body engineering activities, shorten the development cycle of the vehicle body; using engineering methods $\mathrm{Hu}$ Xiaguang database, etc., through the establishment of the Qinghai-Tibet highway for road works project database, the road project activities linked to the level of the Qinghai-Tibet Highway to improve the design to ensure smooth traffic and reduce road maintenance costs; peak line established in Xi'an, Nanjing Railway Survey and Design engineering database systems involving all areas of the design phase of Railway Survey and Design, the system research and development to achieve a package outside the industry survey data from storage to archive query application of the whole process, to better meet the station before and after the integration of professional CAD design requirements; Chen Shutang other established logging class exploration database, from database structure design , logging data processing, format conversion, set the sum of the starting entry techniques for building a database logging class exploration database and data entry provides a feasible solution for the field of engineering geology department full use of logging information resources to provide a better channel.

\section{3S TECHNOLOGY OVERVIEW}

In recent years, $3 \mathrm{~S}$ technology that Remote Sensing (Remote Sensing, referred to as RS), Global Positioning System (Global Positioning System, referred to as GPS), geographic information systems (Geographic Information System called GIS) development and its application in environmental protection for wetlands provide important advanced means. Because of its rapid, real-time spatial information acquisition and analysis capabilities in global change research resources and environment dynamic monitoring, disaster monitoring and prevention and other hot issues of international concern, more and more attention, especially in real-RS technology, large areas characterized by large scale; GPS precise positioning; the combined application and three powerful GIS data collection and spatial analysis, for the protection of wetlands provide important advanced technology [4] (Fig. 1).

$3 \mathrm{~S}$ technology is based on RS, GPS, GIS, based on a new technology will be integrated with other high-tech fields relevant parts of three independent techniques relevant parts to form a whole and organic form. Remote sensing has a strong ability to obtain information collection and is an important means of data sources and updating of GIS; Geographic Information System is to store, query, analysis, simulation, geospatial data output an important tool for the application of remote sensing technology to provide strong support; global positioning system global, all-weather, high precision real-time navigation feature provides accurate spatial positioning information for the RS, GIS. 3S technology integration is based on three complementary organic combination.

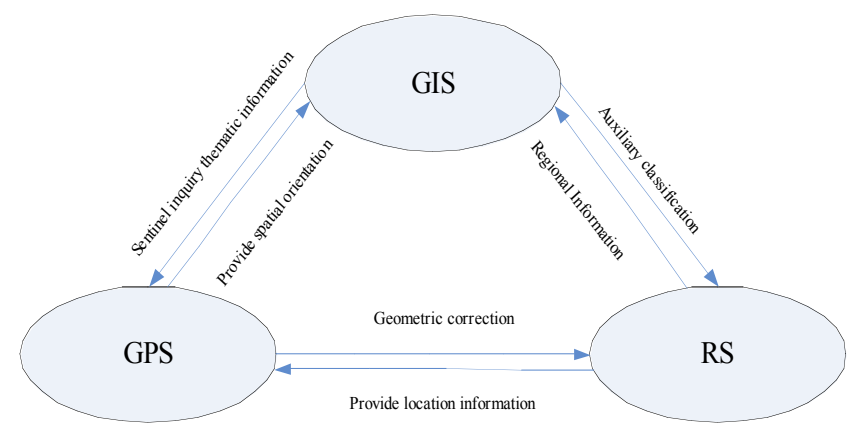

Fig. (1). The Overall Structure of System.

For example, the landscape spatial pattern analysis is generally divided into three steps: First, data collection and processing landscape (such as field trips, measurements, remote sensing, image processing, etc.), followed by the landscape of digitization (two kinds of forms of expression: raster and vector data data), and the appropriate use of research methods to analyze the pattern, and finally explain and comprehensive analysis of the results. Landscape including non-spatial data and spatial data and spatial data can be divided into point pattern (such as the distribution of individual trees), quantitative spatial data (such as biomass) and qualitative spatial data (such as vegetation type map). The main indicators of wetland landscape pattern analysis chosen as follows:

\section{(1) Patch perimeter and area}

The boundary length times area of each patch.

(2) The proportion of the landscape

$$
P_{n}=A_{\mathrm{k}} / A \bullet 100 \%
$$

Where $\mathrm{P}$ is the first class landscape landscape k proportion index, $\mathrm{A}$ is the total area of the $\mathrm{k}$ classes plaque landscape, A is the landscape total system area. The index $\mathrm{k}$ denotes the class of landscape area proportion of the total area of the landscape.

(3) Landscape diversity index

$$
\begin{gathered}
H=-\sum P_{K} \ln P_{K} \\
D=H_{\max }+\sum_{k=1}^{m} P_{K} \ln \left(\mathrm{P}_{\mathrm{k}}\right)
\end{gathered}
$$

Where D is the landscape of the dominance of the first $\mathrm{k}$ $\mathrm{p}$ is the proportion of the area occupied by class landscape types, $\mathrm{m}$ is the number of landscape types, wipe Hmax is the maximum diversity index, Hmax's role is to make the number of different types of landscape elements through the landscape differences standardization. D value is large, said the landscape only by one or a few types of landscape domi- 
nated; and D values of hours, it means that the landscape by a roughly equal number of large area consisting of landscapes

(4) Fragmentation Landscape

$$
C=N_{g} / A_{g}
$$

Where, $\mathrm{K}$ is the type of landscape fragmentation $\mathrm{k}$, the number of patches of landscape types from $\mathrm{k}$ and $\mathrm{k}$ of the total area of man-made landscape.

The overall landscape fragmentation expression is:

$$
C=T N / T A
$$

$\mathrm{SN}$ is the landscape in which the total number of workers plaque type $\mathrm{A}$ is the total area of the landscape.

\section{THE APPLICATION OF $3 S$ TECHNOLOGY IN WETLAND}

3S technology in foreign countries started earlier, has been in a relatively mature stage, and widely used in wetland research. In the 1990s, the United States established a Louisiana wetland spatial decision support system for the freshwater wetland conversion, evaluation deposition conversion, marsh management, fixed and other shoreline projects; American scholars in the use of GIS technology to collect, store, analysis, synthesis wetland hydrological modeling required huge amounts of data, and GIS technology to precision test model are explored alluvial plain basin water resources management and planning to establish a hydraulic model [5]; Canada Alain Pietroniro such as the use of multitemporal space-time, multi-platform remote sensing data to monitor changes in the delta wetland hydrological environment, in order to predict the risk of future results and may be subject to changes in wetland ecosystems.

In our country, $3 \mathrm{~S}$ technology has been widely applied in wetland research, aspects of its resources survey in wetlands, wetland dynamic change monitoring, wetland landscape pattern change and wetland biodiversity survey analysis plays an active role, such as ZHANG Zhifeng, etc. Based on GIS and RS technology, the use of multi-source remote sensing image fusion technology and GIS overlay analysis features, human-computer interaction interpretation, drawn in 1998, the status quo of wetland resources Beijing Yeyahu Wetland Nature Reserve and surrounding area of 2005 and 2002; Zhou Huamao etc. to Ruoergai plateau wetland resources for research object, visual interpretation, remote sensing image processing and machine work to help interpret remote sensing classification and mapping, etc., and completed Ruoergai plateau 1:10 square survey of wetland resources, and establishment of wetland resources information management system; Liu Man, etc. in 1986 and 2000 remote sensing images as the basic source of data on RS and GIS technical support, for the Northeast wetland resources dynamically change monitoring; ZHAO Wei, etc. by Yeyahu wetlands TM IRS images and image processing, to obtain two thematic maps of land use, and then analyzed using GIS technology, get Yeyahu wetland land use and cover change in circumstances; Wang Aihua, such as landscape ecology theory, using RS and GIS phase a combination of methods to explore the dynamic characteristics of the Sanjiang Plain Wetlands and landscape analysis, the results showed that from 1980 to 2000 among landscape Sanjiang Plain Wetlands undergone major changes [6].

$3 \mathrm{~S}$ technology in the management of wetlands, mainly in the RS and GPS data to a data source, the use of GIS spatial analysis functions and attribute data management capabilities, the establishment of wetland information system for management of wetland resources.

\section{SYSTEM STRUCTURE DESIGN OF ENGINEER- ING DATABASE}

System Architecture Design mainly OK to submerged plants harvesting project, reeds spread control and dredging, lake deepening project, circulation improvement projects, the lake water and soil conservation projects, the Yellow River water engineering, project development and utilization of aquatic resources for the overall structure, the ecological Engineering by basic data management, planning and design, project management, dynamic analysis, ecological monitoring, mapping and information query output subsystem design. Study on Regional Ecological Engineering Database overall structural design, shown in Fig. (2).

\section{ENGINEERING DATABASE DESIGN}

Database design for a given application environment, construct the optimal database schema, the establishment of databases and applications, to enable them to efficiently store data to meet a variety of user applications. Specifically, that is, for a given application environment and provide a logical design to determine the optimal data model and processing modes, as well as a database storage structures and access methods to determine the physical design, build to achieve real-world information and database information contact, meet user requirements, a data management system that can be accepted by the system at the same time to achieve goals and effectively manage the database [7].

Regional Ecological Engineering Data Research database can be divided into spatial data and attribute data. Spatial data mainly topographic maps, ecological engineering maps, remote sensing image at different times and in the form of thematic maps, including graphic data and attribute data inside. Spatial database design includes basic geographic graphic information layers, layers of administrative divisions, each project information layer, the layer engineering progress, thematic layers and so on.

Attribute data including structured and unstructured data. Structured data is expressed in the form of data tables available relational database tables, views expressed, such as a variety of ecological engineering schedules, tables, etc; and unstructured data mainly some documents, multimedia data, such as engineering analysis report, project planning, etc. These data are into the document data, the establishment of the document database. Establish property database includes various studies wetland area of basic data attribute information, property information and monitoring information engineering, and database software SQL Server2000 established by forming property database. 
The Ecology Engineering Database

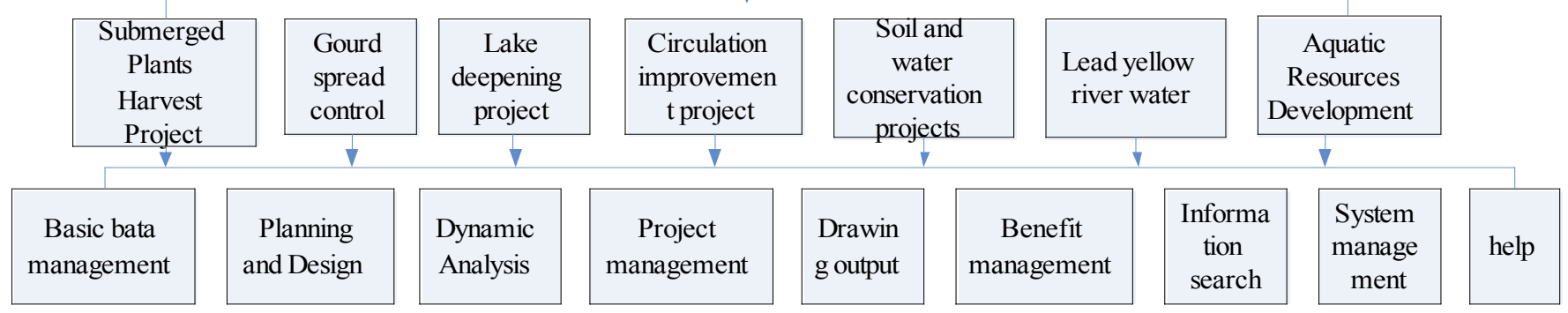

Fig. (2). The Overall Structure of System.

\section{DESIGNE AND IMPLEMENTION OF SYSTEM FUNCTIONS}

\subsection{Basic Data Management Subsystem}

Data management subsystem includes several modules project data, public data and documentation data. Module is mainly used to store project data and research related to the foundation of regional ecological engineering data; public data module is used to store information on basic ecological research areas, such as the study area water quality information, weather information; document data module is mainly used to store and ecology documentation related to the project, the establishment of this subsystem is mainly for applications other modules to establish a data base.

\subsection{Project Management Subsystem}

Project management subsystem includes task management, financial management, and file management module. The subsystem can be achieved through ecological engineering information to browse and make schedule changes, preparation of project, providing different levels of progress reports and status inquiry, engineering pre-settlement and other functions. For example, in the study area of ecological management, the need to establish reed zone air ducts and through waterways, the use of GPS in the establishment of the plenum and through waterways to locate, through which the transport subsystem collected data into the database, automatic format conversion, get electronic map, you can clean the air ducts regularly and accurately through the waterway [8].

\subsection{Dynamic Analysis Subsystem}

Dynamic analysis subsystem includes engineering statistics, statistics and statistical analysis. With the progress of ecological engineering, spatial and attribute information will change, including changes in the topography of the study area, reed harvesting area, the project progress data, quality data and investment data updates. Through dynamic analysis subsystem, the user can primitive drawings according to the situation on the add, delete, modify, and save the editing and replenish and modify attribute data. Users may also be needed for data backup, so that if necessary, to recover all or part of the data over a certain time, while achieving historical queries and data comparison operations.

\subsection{Drawing Output Subsystem Mapping}

Output subsystem includes thematic map production, graphic output, report output modules. Thematic map production module, you can use the module production of thematic maps; ecological engineering construction plans, progress chart can be output directly through the graphical output module; report output can be a database of basic data and information, statistics, analysis, use SQL forms processing capabilities Server by using the method call SQL Server of Visual Basic, the data output.

\section{THE ANALYSIS OF SYSTEM OUTPUT}

Accuracy evaluation is to compare two images, one of which is the evaluation of remote sensing image classification to be, and the other is to assume a precise reference to Figs. (1) and (2). Accuracy evaluation is best to compare the two images like consistency between each cell. But in most cases, it is difficult to obtain an accurate reference map the whole, most of the accuracy of the evaluation are part of the image pixel sampling to evaluate its reference category through fieldwork, more detailed aerial photographs, or get on other sources classification map. Classification of remote sensing image classification accuracy assessment is one of the most important steps, there is no classification of remote sensing image classification accuracy assessment results are almost worthless. When digitizing; registration error reference data and remote sensing classification map: there are some errors between the classification and the ground reality is always, but some classification errors and not just divide caused by wrong, must consider the following factors erroneous reference point; establish the accuracy of data entry errors when evaluating database; visual image interpretation errors; remote sensing satellite after crossing the field of land use changes resulting work field data and image data does not match; remote sensing image mapping errors.

Error matrix (also called confusion matrix) is a standard format used to represent the remote sensing image classification accuracy evaluation. Error matrix is a matrix of $\mathrm{N}$ rows $\times \mathrm{N}$ columns, where $\mathrm{N}$ represents the number of categories, can generally be represented in the form of Table $\mathbf{1}$.

For database output, the basic statistics include:

(1) The overall classification accuracy. Divided by the total number of correct classification reference number is calculated as follows: 
Table 1. The error matrix.

\begin{tabular}{|c|c|c|c|c|c|c|c|}
\hline \multirow{2}{*}{ Classification } & \multicolumn{4}{|c|}{ Reference data } & \multirow{2}{*}{ Line sume } & \multirow{2}{*}{ User accurancy } & \multirow{2}{*}{ Kappa } \\
\hline & 1 & 2 & $\ldots$ & $\mathbf{n}$ & & & \\
\hline 1 & $\mathrm{P}_{11}$ & $\mathrm{p}_{21}$ & $\ldots$ & $\mathrm{Pn}+1$ & & & \\
\hline$\ldots$ & $\ldots$ & $\ldots$ & $\ldots$ & $\ldots$ & & & \\
\hline $\mathrm{n}$ & $\mathrm{P}_{1 \mathrm{n}}$ & $\mathrm{P} 2+\mathrm{n}$ & & $\mathrm{Pn}+\mathrm{n}$ & & & \\
\hline Column sum & $\mathrm{P}_{1}+$ & $\mathrm{P}_{2}+$ & & $\mathrm{P}_{\mathrm{n}}+$ & & & \\
\hline
\end{tabular}

$$
P_{n}=\sum_{k=1}^{n} p_{k k} / p
$$

(2) the accuracy of the producer. The percentage of the reference data are correctly classified, is calculated as:

$$
p_{i j}=p_{i i} / p_{i}+\mathrm{i}
$$

(3) user accuracy. In the same class, the number of correctly classified in this category as a percentage of the total, represents an element can be classified as true representatives of the probability of this kind. The formula is:

$$
p_{j i}=p_{i i} / p_{i}+j
$$

(4) Kappa coefficient is a classification accuracy of statistical values, the range between 0 and 1 . This classification indicates that compared with the random use of each pixel is assigned to any one class much better. The formula is

$$
K=\frac{P \cdot \sum_{k=1}^{n} P_{K K}-\sum_{i=1}^{n}\left(p+i \cdot p_{i}+\right)}{p^{2}-\sum_{i=1}^{n}\left(p+i \cdot p_{i}+\right)}
$$

The future, we can classify the results of the two imagebased object-oriented classification according to a random distribution throughout the class sampling, combined with field data mining point, thematic maps and visual aid involved in the interpretation of data to determine the accuracy of evaluating the true value of the image of the study area, With this true value image classification accuracy test work results graph. However, due to space limitations, this paper do not make too much explanation.

\section{CONCLUSION}

Traditional wetland study was to obtain wetland types, size and spatial distribution of information through field observations and the amount of calculation. This traditional research techniques work efficiency is relatively low, were only a small area of wetlands in-depth study. Development of remote sensing technology and Gls for regional wetland study provides a new way. The use of multi-band remote sensor, not only can be observed from the air directly to the spatial distribution of wetlands, while also revealing the intrinsic quality of wetlands through different band characteristics. Long continuous observation phase can form a dynamic monitoring of wetland. Therefore, remote sensing and GIS technology is becoming an important means of wetland research.

In this paper, 3S technology is used to build a database of wetland ecological overview and stress the importance of information technology, but only use the information technology and actual research associate, in the pursuit of the accuracy of the premise, can we effectively use the database.

\section{CONFLICT OF INTEREST}

The authors confirm that this article content has no conflict of interest.

\section{ACKNOWLEDGEMENTS}

Declared none.

\section{REFERENCES}

[1] P. M. Atkinson, "Spatially Weighted Supervised Classification for Remote Sensing," International Journal of Applied Earth Observation and Geoinformation, vol. 5, no. 4, pp. 277-291, 2004.

[2] A. Lobo, O. Chic, and A. Casterad, "Classification of Mediterranean Crops with Multisensor Data Per-pixel Versus Per-object Statistics and Image Segmentation," International Journal of Remote Sensing, vol. 17, no. 12, pp. 2385-2400, 1996.

[3] C. J. van der Sande, S.M. de Jong, and A.P.J. de Roo, "A Segmentation and classification Approach of IKONOS-Imagery for Land Cover Mapping to Assist flood Risk and Flood Damage Assessment," International Journal of Applied Earth Observation and Geoinformation, vol. 4, no. 3, pp. 217-229, 2003.

[4] E.M. Patrick, "Theory and Methods for Modeling and Evaluating Multiscale Landscape Struetures," Intemational Archives of Photogrammetry and Remote Sensing, vol. 78, pp. 120-123, 2001.

[5] L. B. Bronge, and B. Naslund-Landenmark, "Wetland classification for Swedish CORINE Land Cover adopting a semi-automatic interactive approach," Canadian Journal of Remote Sensing, vol. 28, no. 2, pp. 139-155, 2002.

[6] A. Ballard, and C. M. Brown, "Computer Vision," Englewood Cliffs. Prentice-Hall Inc, vol. 88, pp. 99-102, 1982.

[7] P. Aplin, "Remote sensing:Land cover," Progress in Physical Geography, vol. 28, no. 2, pp. 283-293, 2004.

[8] J N. Robert, M. J. H. Frank, and M. Marcel, "Increasing flood risk and wetland losses due to global sea level rise," Global Environmental Change, no. 9, pp. 67-87, 1999. 